\title{
Synthesis of poly(amidoamine)-graft-poly(methyl acrylate) magnetic nanocomposite for removal of lead contaminant from aqueous media
}

\author{
A. Pourjavadi ${ }^{1}$ A. Abedin-Moghanaki ${ }^{1}$ S. H. Hosseini ${ }^{1}$
}

Received: 7 November 2015/Revised: 12 April 2016/Accepted: 28 June 2016/Published online: 7 July 2016

(C) Islamic Azad University (IAU) 2016

\begin{abstract}
Poly(amidoamine)-graft-poly(methyl acrylate) magnetic nanocomposite was synthesized via radical polymerization of methyl acrylate onto modified magnetic nanoparticles followed by the functionalization of the methyl ester groups with poly(amidoamine) dendrimer. The resulting poly(amidoamine)-graft-poly(methyl acrylate) magnetic nanocomposite was then characterized by infrared spectroscopy, transmission electron microscopy, thermogravimetric analysis, scanning electron microscope and X-ray diffraction analysis. Its application as an adsorbent for the removal of $\mathrm{Pb}(\mathrm{II})$ ions was studied. The removal capability of the adsorbent was investigated in different $\mathrm{pH}$ values, contact time (kinetics) and initial concentration of lead. Moreover, adsorption isotherms were investigated to describe the mechanistic feature of this nanocomposite for adsorption. Accordingly, its high adsorption capacity $(310 \mathrm{mg} / \mathrm{g})$ and efficient adsorption toward lead ions in aqueous solution were shown. To further study of the chemistry behind the adsorption process, a comprehensive density functional theory-based study was
\end{abstract}

Electronic supplementary material The online version of this article (doi:10.1007/s13762-016-1063-7) contains supplementary material, which is available to authorized users.

\section{A. Pourjavadi}

purjavad@sharif.edu

1 Polymer Research Laboratory, Department of Chemistry, Sharif University of Technology, Azadi Avenue, P.O. Box 11365-9516, Tehran, Iran performed, and a relatively strong interaction between metal ions and adsorbent was observed based on the calculated adsorption free energies.

Keywords Magnetic nanocomposite - Adsorption · Poly(amidoamine) dendrimer · Poly(methyl acrylate)

\section{Introduction}

In the recent decades, various environmental contaminants especially water pollutants have been increased due to the development of industries and factories. Heavy metals, dyes and other organic compounds such as pesticides, polycyclic aromatic hydrocarbons and organochlorines are among the most important hazardous water contaminants. Among these contaminants, heavy metals are not biodegradable and tend to accumulate in living organisms. Many heavy metal ions are known to be toxic or carcinogenic at even relatively low concentrations (Wu et al. 2010; Zhang et al. 2013a; Repo et al. 2013). Lead is especially regarded as one of the most hazardous metals for human health, which can cause basic cellular process damages. It can also damage on the central nervous system, brain, kidney, liver and reproductive system (Gurer-Orhan et al. 2004; Campbell et al. 1981).

Nowadays, numerous well-known methods such as chemical precipitation (Pang et al. 2011), membrane filtration (Song et al. 2011), ion exchange (Wdjtowicz and Stokmosa 2002), electrochemical treatment technologies (Belkacem et al. 2008) and adsorption (Jiang et al. 2015; Ghaffari et al. 2015; Tan et al. 2012; Mahmoud et al. 2013) have been extensively explored for the removal and extraction of heavy metals from 
water/wastewater media. Among these water treatment methods, adsorption is one of the most effective and economic routes that have been widely used for removal of heavy metals. Various adsorbents have been applied for heavy metals uptake from contaminated water, such as activated carbon (Lee et al. 2015a), multiwalled carbon nanotubes (Kosa et al. 2012), mesoporous silica (Heidari et al. 2009; Lee et al. 2015b), agricultural wastes (Minamisawa et al. 2004), biomass and polymeric materials (Reddad et al. 2002; Ge et al. 2012). However, high price, poor regeneration, unfavorable selective adsorption and separation problem have limited the application of the mentioned adsorbents (Zhang et al. 2013a). Therefore, it is an essential subject for environmental researchers and chemists to improve the adsorption capacity, selectivity, simple recovery and easy separations of the adsorbents.

The use of magnetic nano-sized materials is one of the improved methods. Magnetic nanoparticles (MNPs) have attracted much interest, due to their potential applications such as reusability, fast kinetics and reactivity for contaminant removal. In addition, MNPs facilitate separation of adsorbent from aqueous solution using an external magnetic field (Tang and Lo 2013). Nevertheless, in order to increase its adsorption capacity and stability against acidic and alkaline media, the surface of nanoparticles was modified by some organic compounds such as glycine (Zhang et al. 2013b), natural polymers, e.g., chitosan (Liu et al. 2009) and its derivatives, poly(1-vinylimidazole) (Shan et al. 2015) as well as some copolymers, e.g., acrylic acid and crotonic acid (Ge et al. 2012). However, disadvantages such as their low surface area and long contact time limited their use in practical wastewater treatment applications (Badruddozaa et al. 2013; Crini 2005).

In this work, we fabricated a magnetic nanocomposite based on cross-linked poly (methyl acrylate) (MNC) that its surface functionalized with poly(amidoamine) dendrimer (PAMAM). Functionalization with PAMAM enhances the adsorption capacity of the adsorbent (PAMAM-MNC) compared with the other adsorbent due to increasing active sites for absorbance. Moreover, the spent contact time for the $\mathrm{Pb}^{2+}$ removal using PAMAMMNC adsorbent is shorter compared with previously reported adsorbents such as activated carbon, clay minerals and other magnetic adsorbent. Adsorption ability of the prepared adsorbent on $\mathrm{Pb}(\mathrm{II})$ ions was also explored using computational method.
This research was done in polymer laboratory, Department of Chemistry, Sharif University of Technology, during the years of 2013-2015.

\section{Materials and methods}

\section{Materials}

Ferric chloride $\left(\mathrm{FeCl}_{3} \cdot 6 \mathrm{H}_{2} \mathrm{O}\right)$, ferrous chloride $\left(\mathrm{FeCl}_{2} \cdot 4\right.$ $\mathrm{H}_{2} \mathrm{O}$ ), lead(II) nitrate $\left(\mathrm{Pb}\left(\mathrm{NO}_{3}\right)_{2}\right)$, ammonia (30\%), sodium hydroxide $(\mathrm{NaOH})$, hydrochloric acid, tetraethyl orthosilicate (TEOS), (3-aminopropyl)trimethoxysilane (APTS) and $N, N^{\prime}$-methylenebisacrylamide (MBA) were purchased from Merck. Analytically pure methyl acrylate (MA) and ethylenediamine (EDA) were obtained from East of China Chemical Corporation. 2,2-Azobisisobutyronitrile (AIBN) was purchased from Daejung Chemical and Metal Company in Korea. All solvents were analytical grade, and distilled water was used.

\section{Preparation of magnetic nanocomposite}

Initially, the silica-coated $\mathrm{Fe}_{3} \mathrm{O}_{4}$ magnetic nanoparticles (MNPs) were prepared according to the previously reported procedure (Lu et al. 2007). The MNPs were then modified with APTS to establish amine groups. Typically, $2 \mathrm{~g}$ MNP was suspended in $60 \mathrm{~mL}$ toluene by ultrasonication bath. Four milliliters APTS was then added and the mixture was refluxed under stirring for $20 \mathrm{~h}$. The modified MNP- $\mathrm{NH}_{2}$ was magnetically collected and washed three times with ethanol as well as dried at $40{ }^{\circ} \mathrm{C}$.

To prepare magnetic nanocomposite, $0.5 \mathrm{~g} \mathrm{MNP}-\mathrm{NH}_{2}$ was dispersed in $20 \mathrm{~mL}$ dry chloroform. Five grams methyl acrylate and $0.35 \mathrm{~g}$ MBA were added to the above mixture. After $10 \mathrm{~min}, 0.09 \mathrm{~g}$ AIBN was added to the solution to initiate the polymerization reaction and the gelation process completed within $2 \mathrm{~h}$. The obtained magnetic nanocomposite (MNC) was magnetically separated and washed three times with methanol.

Finally, in order to establish active sites on the MNC for the adsorption of metal ions, the surface of MNC was modified with PAMAM dendrimer. Grafting of PAMAM dendrimer onto the surface of nanocomposite was performed via method proposed by Tomalia (Bourque et al. 1999; Pourjavadi et al. 2012). EDA and MA were used to functionalize the MNC according to the following procedure. Two grams MNC was milled and dispersed in methanol. 
Excess amount of EDA $(6 \mathrm{~mL})$ was added to the mixture, and the mixture was refluxed under continuous stirring for 3 days. The obtained product (MNC-G1) was magnetically separated and washed with methanol. The resulted MNC-G1 was dispersed again in methanol, and excess amount of MA $(6 \mathrm{~mL})$ was added to flask and the mixture refluxed for 2 days. Then, the product (MNC-G1') washed with methanol and dried at $50{ }^{\circ} \mathrm{C}$. The last two steps were repeated twice for the formation of the next generations of PAMAM dendrimer (MNC-G2', MNC-G3' and PAMAM-MNC). Final product (PAMAM-MNC) was magnetically separated, washed thoroughly with methanol and dried at $50{ }^{\circ} \mathrm{C}$.

\section{Characterization}

Thermogravimetric analysis (TGA) of samples was recorded under a nitrogen atmosphere by a TGA Q 50 thermogravimetric analyzer. Infrared (IR) spectra of all samples were obtained from $\mathrm{KBr}$ pellets and using an ABB Bommem MB-100 spectrometer. A TOPCON002B electron microscope was used for taking transmission electron microscopy (TEM) images. The morphology of products was studied by scanning electron microscope (SEM) Philips, XL30. Rigalcu D/Max-3c $\mathrm{X}$-ray diffractometer was used for acquiring XRD pattern. CHN analyses were performed with LECO TRUSPEC elemental analyzer. Varian AA-220 Atomic absorbent spectrophotometer was applied for determination of the concentration of metal ions in aqueous solution.

\section{Adsorption and desorption experiments}

$\mathrm{Pb}^{2+}$ ions adsorption experiments were performed in aqueous solution. The effect of $\mathrm{pH}$, contact time, initial concentration and adsorbent amount on adsorption behavior was investigated according to the following procedures. Examining each parameter except adsorbent amount was carried out by adding $10 \pm 1 \mathrm{mg}$ adsorbent into $10 \mathrm{~mL} \mathrm{~Pb}^{2+}$ aqueous solution at room temperature and constant rate $300 \mathrm{rpm}$. The other effective parameters were kept constant during the evaluation of each parameter. At the end of each step, the adsorbents were separated by external magnetic field and residual concentrations of $\mathrm{Pb}^{2+}$ in solution specified using atomic absorption spectroscopy.

The metal adsorption capacity is calculated by Eq. (1):

$Q=\frac{\left(C_{0}-C_{\mathrm{e}}\right) V}{m}$

where $Q(\mathrm{mg} / \mathrm{g})$ is adsorption capacity, $V(\mathrm{~L})$ is the volume of the $\mathrm{Pb}^{2+}$ solution, $m(\mathrm{~g})$ is the adsorbent amount and $C_{0}$ $(\mathrm{mg} / \mathrm{L})$ and $C_{\mathrm{e}}(\mathrm{mg} / \mathrm{L})$ are the initial and equilibrium concentration of $\mathrm{Pb}^{2+}$ in solution, respectively.

In order to study the reusability of PAMAM-MNC adsorbent, $0.3 \mathrm{~g} \mathrm{~Pb}$ (II)-loaded adsorbent was stirred into $100 \mathrm{~mL}$ of $0.1 \mathrm{M} \mathrm{HCl}$ for $10 \mathrm{~min}$ which is an optimal regenerating media for desorption of magnetic core adsorbent (Zhang et al. 2013a). Then, the adsorbent was magnetically separated and washed with methanol and water to remove unabsorbed $\mathrm{Pb}^{2+}$ and excess $\mathrm{HCl}$. The recycled adsorbent was reused for next adsorption runs. This process was repeated five times.

\section{Computational section}

The adsorption free energies of $\mathrm{Pb}^{2+}$ and $\mathrm{Cd}^{2+}$ with a segment of PAMAM were calculated by Spartan 06 (Spartan '06V102'). The geometry optimization was performed by B3LYP/6-311++G(d,p) basis set for $H, C, N$ and $O$ atoms and LANL2DZ basis set for $\mathrm{Pb}^{2+}$ and $\mathrm{Cd}^{2+}$ ions. All minima were confirmed by the presence of only real vibrational frequencies, and the adsorption free energies were calculated by the following Eq. (2):

$\Delta G_{a d \ldots M^{2+}}=G_{a d \ldots M^{2+}}-G_{a d}-G_{M^{2+}}$

See supporting information for a summary of the optimized geometry of structures.

\section{Results and discussion}

\section{Preparation and characterization of the adsorbent}

At the beginning of this study, it was found that the synthesis of PAMAM-MNC proceeded via three steps: (1) formation of iron oxide nanoparticles via co-precipitation method, then coating of the generated iron oxide with APTS; (2) the synthesis of MNC magnetic nanocomposite; (3) modification of MNC with PAMAM dendrimer.

In the first step, the simultaneous presence of $\mathrm{Fe}^{2+}$ and $\mathrm{Fe}^{3+}$ ions in solution of ammonia leads to formation of $\mathrm{Fe}_{3} \mathrm{O}_{4}$ nanoparticles precipitate, as reported earlier (Tang et al. 2009). The generated $\mathrm{Fe}_{3} \mathrm{O}_{4}$ nanoparticles were then coated by silica, following by enrichment of their surface with amine functionality using APTS coating agent.

In the next step, MNC was prepared by cross-linking copolymerization of MA and MBA in the presence of $\mathrm{MNP}-\mathrm{NH}_{2}$. Notably, during the polymerization, magnetic nanoparticles were entrapped within the polymer matrix. Polymer chains were covalently bonded to magnetic nanoparticles by amidation of ester groups. 
Scheme 1 Synthetic route of magnetic nanocomposite (MNC) and propagation of PAMAM dendrimer onto the surface of MNC
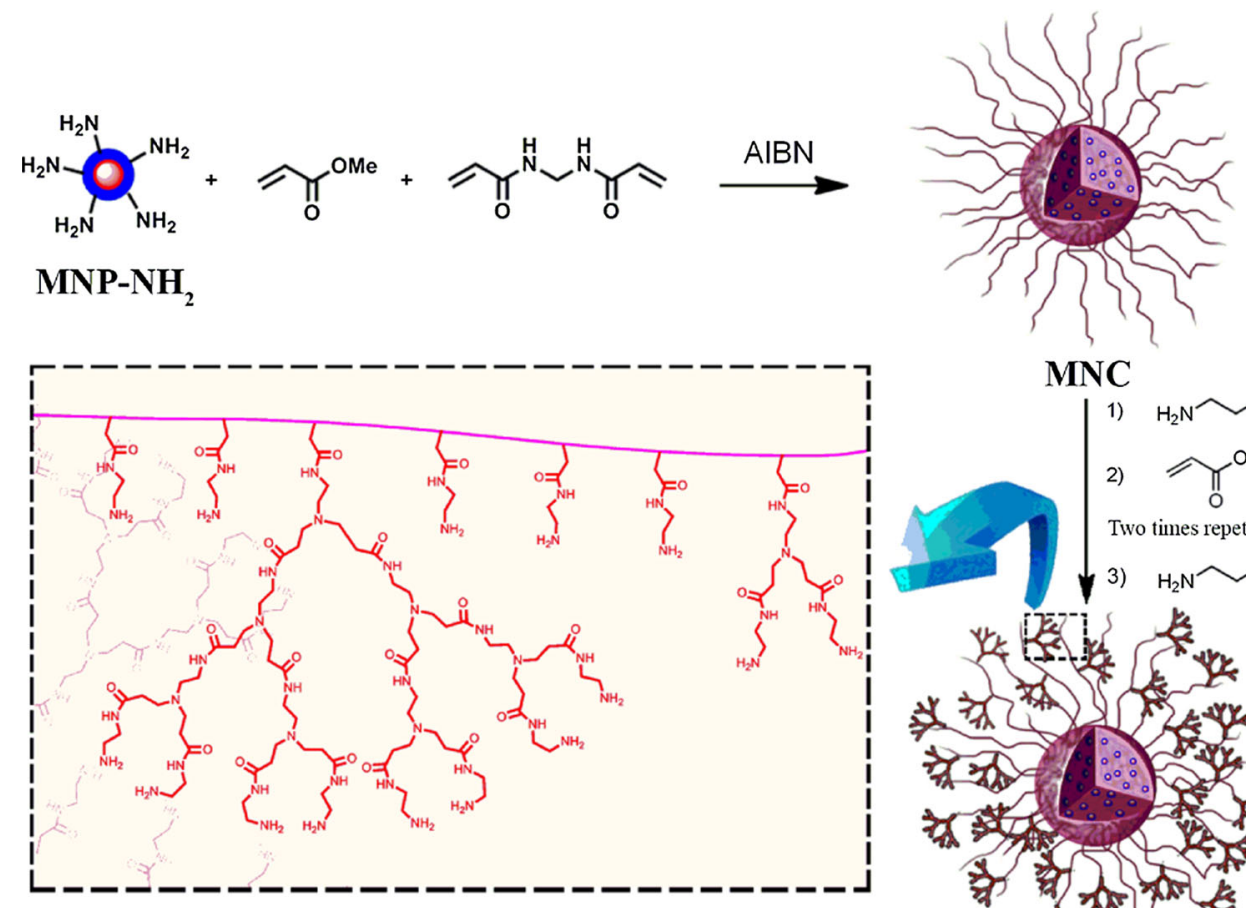

MNC

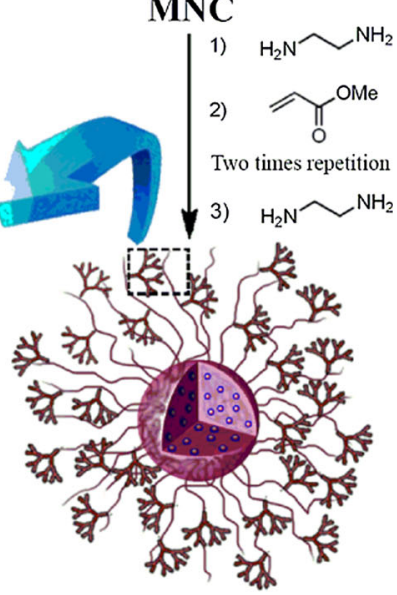

Table 1 Results of CHN analysis

\begin{tabular}{lrrr}
\hline Compound & $C(\%)$ & $H(\%)$ & $N(\%)$ \\
\hline MNP-NH 2 & 7.041 & 1.042 & 0.738 \\
MNC & 34.660 & 6.040 & 11.890 \\
PAMAM-MNC & 47.810 & 7.936 & 20.280 \\
\hline
\end{tabular}

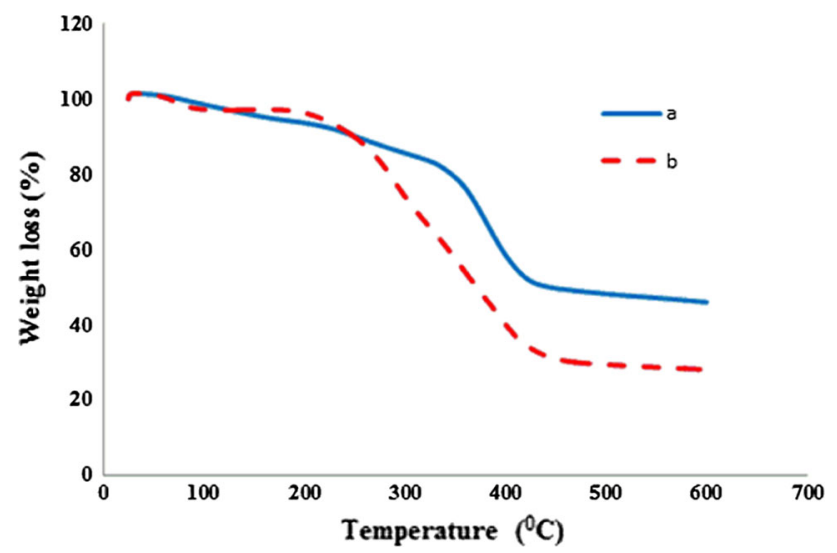

Fig. 1 TGA curves of MNC (a) and PAMAM-MNC (b)

In the final step, propagation of PAMAM dendrimer up to the third generation was carried out via the methods pioneered by Tomalia (Bourque et al. 1999;

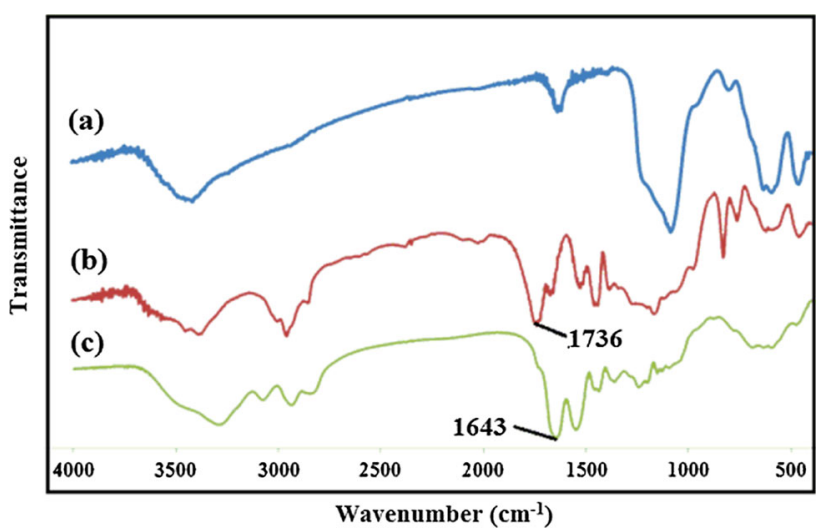

Fig. 2 IR spectra of MNP-NH $($ a), MNC (b) and PAMAM-MNC (c)

Pourjavadi et al. 2012). Accordingly, the ester groups of MNC react with the excess amount of EDA. Then, to form amino propionate ester on the MNC (MNC-G1'), a Michael-type addition was performed between $-\mathrm{NH}_{2}$ groups on the surface of nanocomposite and methyl acrylate. In order to complete the first generation, subsequent amidation reaction was performed with ester groups on the surface of MNC-G1' with EDA. Importantly, the second and third generations of the PAMAM dendrimer on the surface of nanocomposite are formed via application of the last two reactions. The synthesis of 
MNC and its modification with PAMAM dendrimer are shown in Scheme 1.

The results of $\mathrm{CHN}$ analysis for $\mathrm{MNP}-\mathrm{NH}_{2}, \mathrm{MNC}$ and PAMAM-MNC are reported in Table 1. It is clear that, in each step of synthesis of nanocomposite, the percentage of carbon and nitrogen increased. These results in turn confirm that the MNC was successfully modified by PAMAM.

Figure 1 displays the TGA curves of MNC and PAMAM-MNC. In both TGA curves, the weight losses below $150{ }^{\circ} \mathrm{C}$ related to loss of the physically adsorbed water molecules. The weight loss from 150 to $600{ }^{\circ} \mathrm{C}$ was attributed to the thermal degradation of organic content of sample. The larger weight loss of the PAMAM-MNC compared with $\mathrm{MNC}$ is due to the thermal decomposition of grafted dendrimer on the MNC. The content of PAMAM dendrimer was obtained about $18 \mathrm{wt} \%$ according to the TGA curves.

In addition, to confirm the structure of products at each step of the synthesis of adsorbent, particularly in the development of PAMAM dendrimer onto the MNC nanocomposite, the FTIR analysis is performed (Fig. S1, see supporting information). The IR spectra of MNP$\mathrm{NH}_{2}, \mathrm{MNC}$ and PAMAM-MNC are shown in Fig. 2. In this regards, the spectrum of $\mathrm{MNP}-\mathrm{NH}_{2}$ indicates vibrations of $\mathrm{Fe}-\mathrm{O}$ in 613 and $464 \mathrm{~cm}^{-1}$. The presence of peaks at 798, 1104, 2940 and $3450 \mathrm{~cm}^{-1}$ is attributed to $\mathrm{N}-\mathrm{H}$ wagging, $\mathrm{Si}-\mathrm{O}-\mathrm{Si}$ bonding, aliphatic $\mathrm{C}-\mathrm{H}$ stretching and $\mathrm{N}-\mathrm{H}$ stretching vibration, respectively (Tan et al. 2012). Moreover, the peak of $\mathrm{Fe}-\mathrm{O}-\mathrm{Si}$ bond overlaps with $\mathrm{Fe}-\mathrm{O}$ bond peak in the range of $565-585 \mathrm{~cm}^{-1}$ (Yamaura et al. 2004). As shown in Fig. 2b, MNC formation was confirmed by the presence of peak $1736 \mathrm{~cm}^{-1}$ corresponding to stretching vibration of ester groups. It is important to mention that the ester group peak is disappeared after reaction with EDA (Fig. S1 MNC-G1, G2, G3 and PAMAM-MNC), and it appears again in the IR

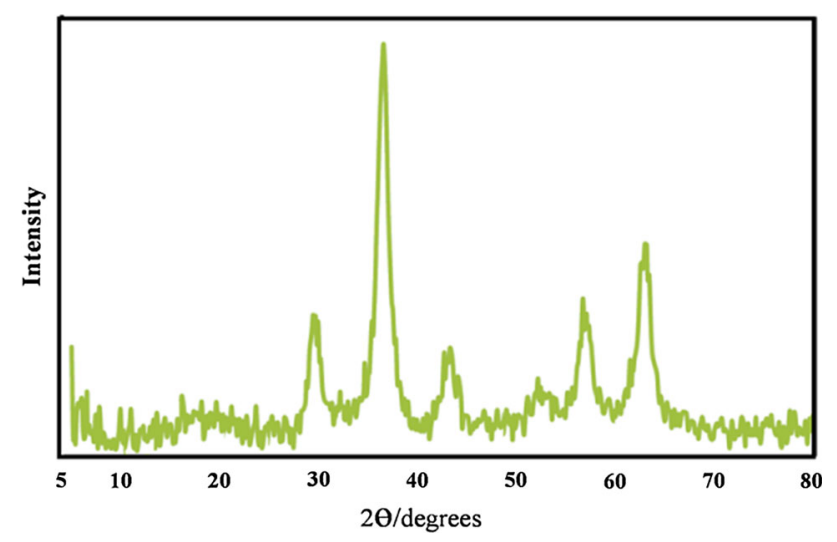

Fig. 3 XRD pattern of PAMAM-MNC spectrum after reaction with methyl acrylate (Fig. S1 MNC-G1', G2' and $\mathrm{G}^{\prime}{ }^{\prime}$ ). The IR spectra of all products are presented in Fig. $\mathrm{S} 1$.

The XRD pattern of PAMAM-MNC is depicted in Fig. 3. Six characteristic peaks of $\mathrm{Fe}_{3} \mathrm{O}_{4}$ (in $2 \theta$ values about 30, 36, 43, 53, 57 and 62) indexed by their indices $(220,311,400,422,511$ and 440) are observed in the XRD pattern of PAMAM-MNC. The broad peak at $2 \theta=20$ is attributed to amorphous silica phase in the nanocomposite structure. Herein, the XRD analysis demonstrates that the crystalline structure of $\mathrm{Fe}_{3} \mathrm{O}_{4}$ has not change during the synthetic steps of adsorbent.

The morphology of PAMAM-MNC, MNC and MNP$\mathrm{NH}_{2}$ was studied via the SEM and TEM analysis, as shown in Fig. S2 and Fig. 4. The SEM image of PAMAM-MNC shows a bulk structure of adsorbent. Moreover, it can be seen that the PAMAM-MNC has a rough surface and distribution of the $\mathrm{Fe}_{3} \mathrm{O}_{4}$ nanoparticles is nearly homogeneous. In TEM image of $\mathrm{MNP}-\mathrm{NH}_{2}$ (Fig. S2b), the dark points represent $\mathrm{Fe}_{3} \mathrm{O}_{4}$ nanoparticles which coated by a gray silica shell, and the TEM image of PAMAM-MNC displays that the dark $\mathrm{MNP}-\mathrm{NH}_{2}$ nanoparticles were distributed in nanocomposite matrix. The diameter of MNP$\mathrm{NH}_{2}$ was around $10-15 \mathrm{~nm}$.

\section{Effect of $\mathrm{pH}$ on adsorption capacity of $\mathbf{P b}^{2+}$}

The $\mathrm{pH}$ of solution is one of the important factors that affect the adsorption behavior, due to its impact on the functional groups of the adsorbent as well as the solubility of the metal ions. Thus, adsorption should be performed in the optimum $\mathrm{pH}$ range. It has been shown that the $\mathrm{Pb}^{2+}$ ions begin to hydrolyze and form $\mathrm{Pb}(\mathrm{OH})_{2}$ and $\mathrm{Pb}(\mathrm{OH})^{+}$ precipitate at $\mathrm{pH}>6$, and the uptake of $\mathrm{Pb}^{2+}$ may be performed with the simultaneous precipitation of $\mathrm{Pb}(\mathrm{OH})_{2}$ and $\mathrm{Pb}(\mathrm{OH})^{+}$(Zhang et al. 2013a; Naiya et al. 2009). Hence, the effect of $\mathrm{pH}$ on adsorption capacity of $\mathrm{Pb}^{2+}$ was studied in the $\mathrm{pH}$ range of 1-6 and known initial concentration of $\mathrm{Pb}^{2+}(600 \mathrm{mg} / \mathrm{L})$. However, as shown in Fig. 5, it is clearly observed that the adsorption amounts of $\mathrm{Pb}^{2+}$ ions enhanced continuously with increasing of the initial $\mathrm{pH}$ of the solution from 1 to 6 and the adsorption amounts decreased at lower degree of $\mathrm{pH}$, due to formation of positively charged $-\mathrm{NH}^{3+}$ and $-\mathrm{NH}_{2}{ }^{+}-$groups on the adsorbent. On the other hand, the tendency of coordination between metal cations and positively charged surface decreased because of a competition between $\mathrm{Pb}^{2+}$ and $\mathrm{H}^{+}$ ions to coordinate with the adsorbent (Scheme 2). However, as $\mathrm{pH}$ value was increased, positive charge density of the adsorbent decreased and its adsorption capacity improved. The maximum adsorption capacity $(310 \mathrm{mg} / \mathrm{g}$ ) of $\mathrm{Pb}^{2+}$ was at $\mathrm{pH} 5-6$. 

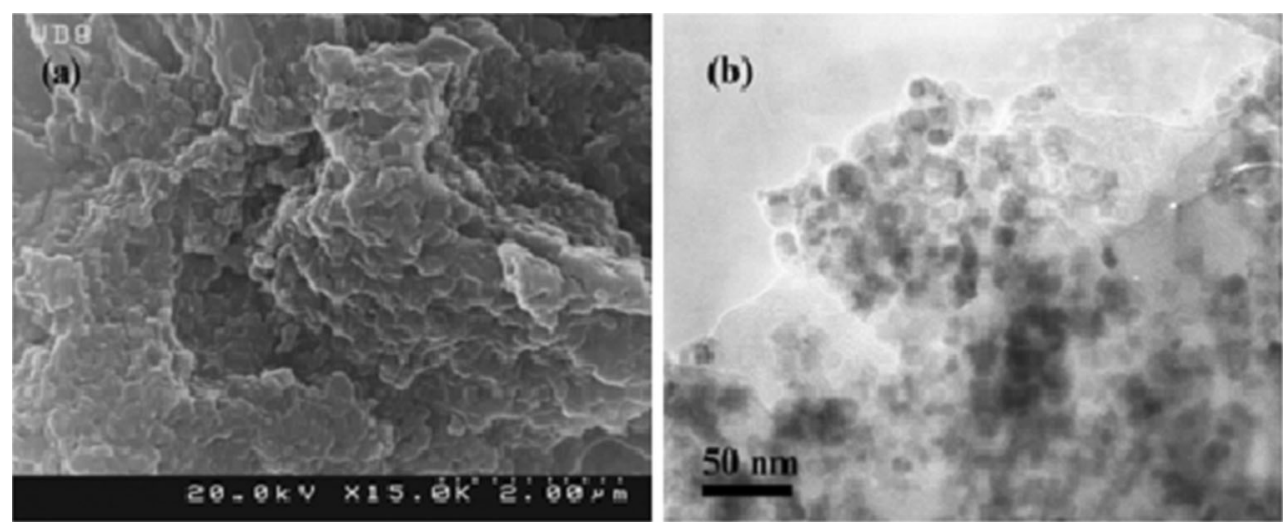

Fig. 4 SEM (a) and TEM (b) images of PAMAM-MNC

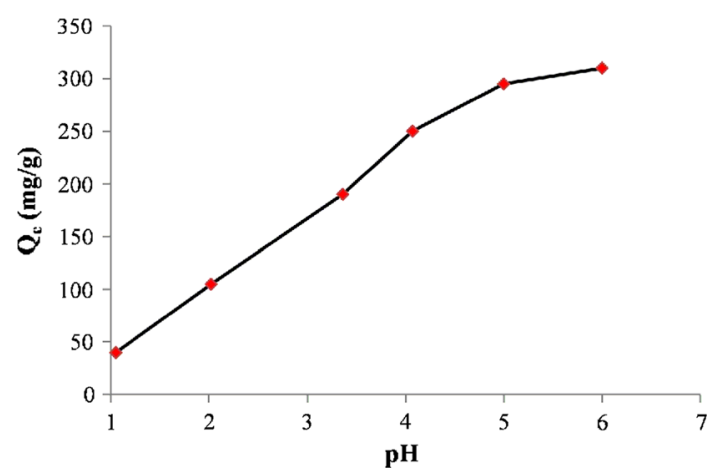

Fig. 5 Effect of solution $\mathrm{pH}$ on the adsorption of $\mathrm{Pb}^{2+}$ from aqueous solution

$-\mathrm{NH}-\left(\mathrm{NH}_{2}\right)+\mathrm{OH}^{-}$

$-\mathrm{NH}-\left(\mathrm{NH}_{2}\right)+\mathrm{H}^{+}$

- $\mathrm{Pb}^{2+}$

- $-\mathrm{NH}_{3}{ }^{+}$or $-\mathrm{NH}_{2}{ }^{+}$

- $-\mathrm{NH}^{-}$or $-\mathrm{N}-$

- $-\mathrm{NH}_{2}$ or $-\mathrm{NH}-$
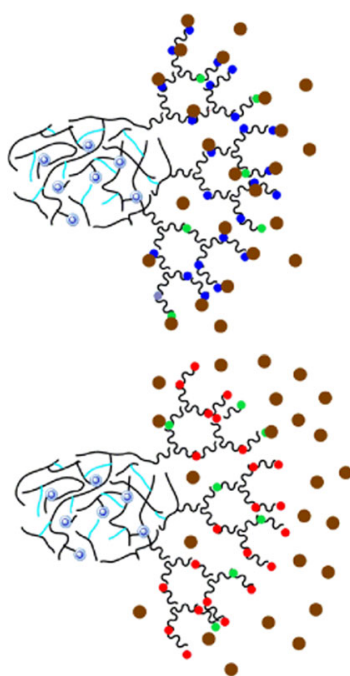

Scheme 2 Removal behavior of adsorbent under acidic and basic conditions
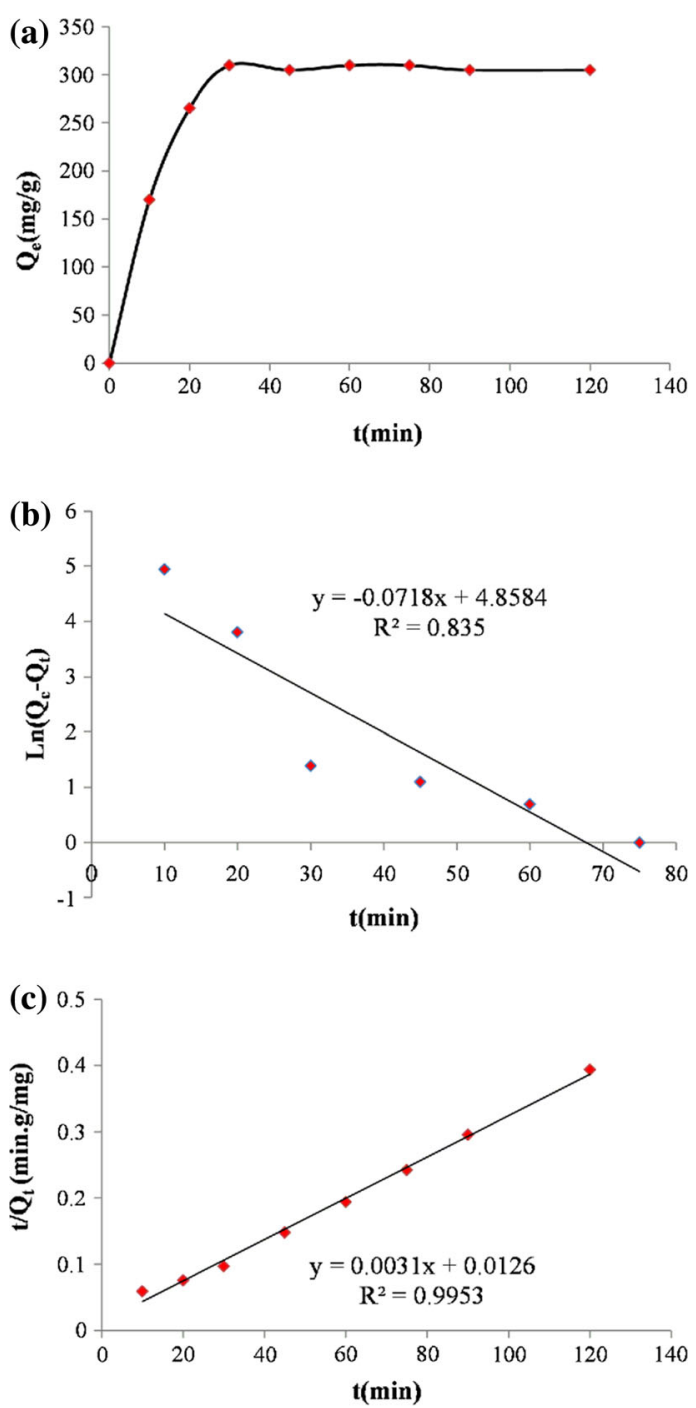

Fig. 6 Effect of contact time on the equilibrium adsorption of $\mathrm{Pb}^{2+}$ from aqueous solution (a) pseudo-first-order (b) and pseudo-secondorder (c) kinetic models for $\mathrm{Pb}^{2+}$ removal by PAMAM-MNC 
Table 2 Comparison of PAMAM-MNC with some previously reported adsorbents

\begin{tabular}{|c|c|c|c|c|}
\hline Adsorbents & $Q(\mathrm{mg} / \mathrm{g})$ & $\mathrm{pH}$ & Time (min) & Refs. \\
\hline $\mathrm{Fe}_{3} \mathrm{O}_{4} @ \mathrm{SiO}_{2}-\mathrm{NH}_{2}$ core shell nanomaterials & 238 & $5-6$ & 480 & Zhang et al. (2013a) \\
\hline Amino-functionalized $\mathrm{Fe}_{3} \mathrm{O}_{4} \mathrm{MNP}$ & 40.1 & 5 & $<3$ & Tan et al. (2012) \\
\hline Nano- $\mathrm{Fe}_{3} \mathrm{O}_{4}-\mathrm{SiO}_{2}-\mathrm{TETA}^{\mathrm{a}}$ & 270 & 7 & 30 & Mahmoud et al. (2013) \\
\hline Cyclodextrin poly-MNPs & 64.5 & $5.5-6$ & 45 & Badruddozaa et al. (2013) \\
\hline Turkish illitic clay & 16.61 & 3 & 100 & Shekinah et al. (2002) \\
\hline Activated carbon prepared from Eichhornia & 239 & 4 & 240 & Ozdes et al. (2011) \\
\hline Amine-functionalized mesoporous MNPs & 369 & 5 & $150<$ & Xin et al. (2012) \\
\hline KIT-6-EDTA ${ }^{\mathrm{b}}$ & 191 & $5-6$ & $<40$ & Ezzeddine et al. (2015) \\
\hline $\begin{array}{l}\text { Tetraoxalyl ethylenediamine melamine chelate } \\
\text { resin grafted coconut active charcoal }\end{array}$ & 47.7 & 5.5 & $>240$ & Jin et al. (2013) \\
\hline Hybrid polymeric nanocomposite & 49.72 & 7 & $<15$ & Alsohaimi et al. (2015) \\
\hline PAMAM-MNC & 310 & $5-6$ & 30 & This study \\
\hline
\end{tabular}

a Triethylenetetramine

${ }^{\mathrm{b}}$ Ethylenediaminetetraacetic acid

Table 3 Kinetic parameters for pseudo-first-order and pseudo-second-order models

\begin{tabular}{|c|c|c|c|c|c|c|c|c|}
\hline & \multirow[t]{2}{*}{$Q_{\mathrm{e}, \operatorname{expt}}(\mathrm{mg} / \mathrm{g})$} & \multicolumn{3}{|c|}{ Pseudo-first-order kinetic model } & \multicolumn{4}{|c|}{ Pseudo-second-order kinetic model } \\
\hline & & $\overline{k_{1}\left(\min ^{-1}\right)}$ & $Q_{\mathrm{e}, \mathrm{cal}}(\mathrm{mg} / \mathrm{g})$ & $R^{2}$ & $v_{0}(\mathrm{mg} / \mathrm{g} / \mathrm{min})$ & $k_{2}(\mathrm{~g} / \mathrm{mg} / \mathrm{min})$ & $Q_{\mathrm{e}, \mathrm{cal}}(\mathrm{mg} / \mathrm{g})$ & $R^{2}$ \\
\hline $\mathrm{Pb}^{2+}$ & 310 & 0.0718 & 128.8 & 0.835 & 79.4 & $7.63 \times 10^{-4}$ & 322 & 0.9953 \\
\hline
\end{tabular}

\section{Effect of contact time and adsorption kinetics}

The contact time is one of the important factors for economical wastewater treatment application (Badruddozaa et al. 2013). The adsorption of $\mathrm{Pb}^{2+}$ by PAMAM-MNC was studied with time ranging from 10 to $120 \mathrm{~min}$. This investigation was performed in known initial concentration of $\mathrm{Pb}^{2+}(600 \mathrm{mg} / \mathrm{L})$ and optimum $\mathrm{pH}$ value 5.5. The results of contact time influence on $\mathrm{Pb}^{2+}$ adsorption are represented in Fig. 6a. It was found that the adsorption takes place during the early stages of the removal process that may be due to the availability and abundance of active sites on the adsorbent surface. The maximum adsorption of $\mathrm{Pb}^{2+}$ ions was obtained almost within $30 \mathrm{~min}$. During the next contact time from 30 to $120 \mathrm{~min}$, the removal rate becomes quite slow through a gradual decrease in the number of active sites of the adsorbent. Interestingly, the contact time for the $\mathrm{Pb}^{2+}$ removal using PAMAM-MNC adsorbent is very short compared with previously reported adsorbents such as activated carbon, clay minerals and other magnetic adsorbent (see Table 2).

The adsorption kinetic of $\mathrm{Pb}^{2+}$ by PAMAM-MNC adsorbent was studied by means of two kinetic models: pseudo-first-order model and pseudo-second-order model according to the following equations:
Pseudo-first-order equation: $\ln \left(Q_{\mathrm{e}}-Q_{t}\right)=\ln Q_{\mathrm{e}}-k_{1} t$

Pseudo-second-order equation: $\frac{t}{Q_{t}}=\frac{1}{k_{2} Q_{\mathrm{e}}^{2}}+\frac{t}{Q_{\mathrm{e}}}$

where $Q_{t}(\mathrm{mg} / \mathrm{g})$ and $Q_{\mathrm{e}}(\mathrm{mg} / \mathrm{g})$ show the adsorption capacity at time $t$ and equilibrium state, respectively, $t$ is the time (min) and $k_{1}$ and $k_{2}$ are the kinetic rate constants ( $\mathrm{g} / \mathrm{mg} \mathrm{min}$ ) of the pseudo-first-order and pseudo-secondorder model (Lagergren 1898; Ho and McKay 1998).

The early adsorption rate $\left(v_{0}\right)$ of $\mathrm{Pb}^{2+}$ was also obtained using pseudo-second-order model according to Eq. (5):

$v_{0}=k_{2} Q_{\mathrm{e}}^{2}$

Figure 6b, c shows the linear plots of $\operatorname{Ln}\left(Q_{\mathrm{e}}-Q_{t}\right)$ versus $t$ and $t / Q_{t}$ versus $t$, respectively. The calculated kinetic parameters for both models are listed in Table 3. Comparison of the correlation coefficients $\left(R^{2}\right)$ derived from both models was revealed that the experimental data are more consistent with the pseudo-second-order model than the pseudo-first-order model. Moreover, the experimental $Q_{\mathrm{e}}$ value is more consistent with the calculated $Q_{\mathrm{e}}$ value from the pseudo-second-order rate equation than those from pseudo-first-order rate equation. 


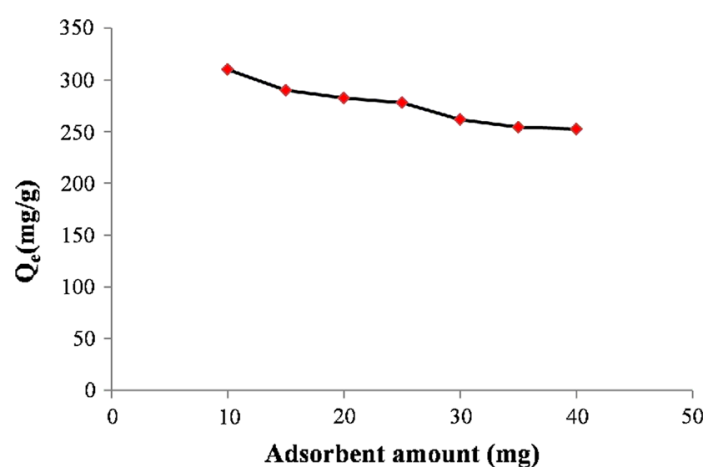

Fig. 7 Effect of adsorbent amount on the equilibrium adsorption of $\mathrm{Pb}^{2+}$
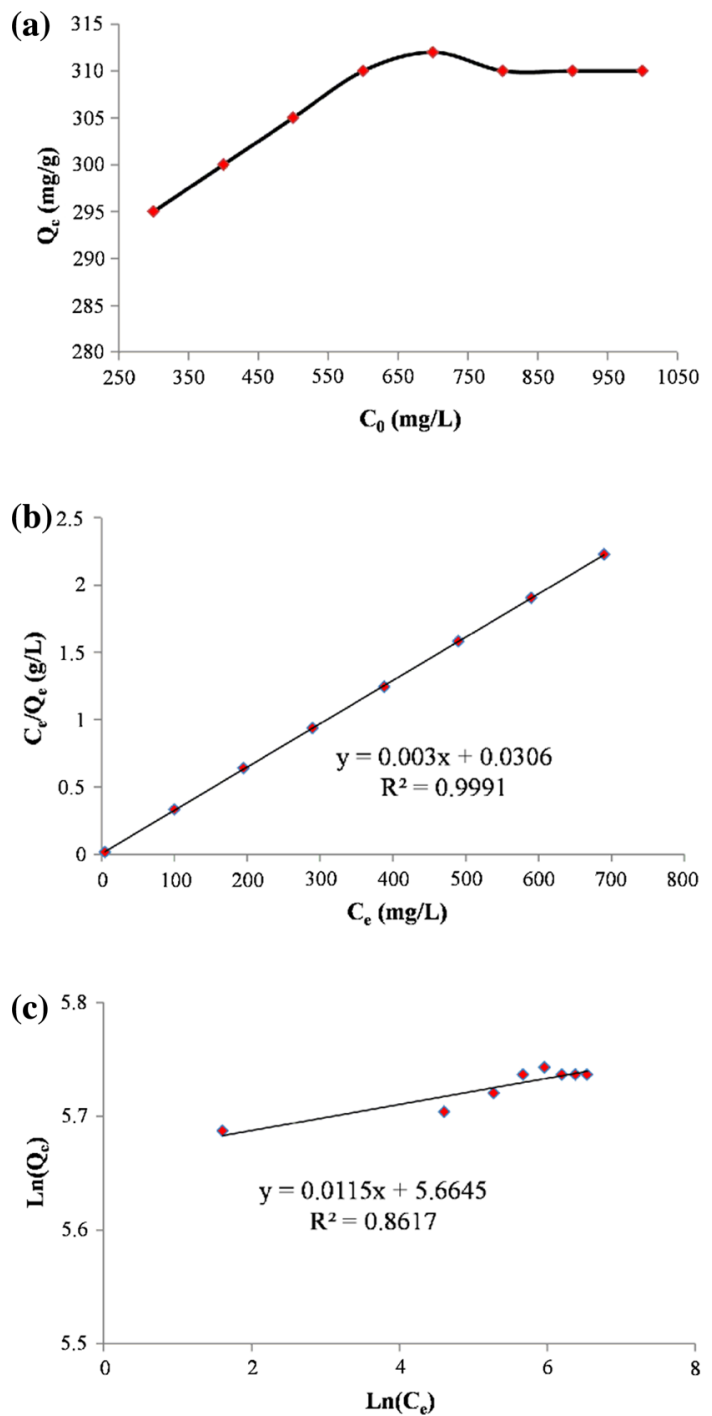

Fig. 8 Effect of $\mathrm{Pb}^{2+}$ initial concentration on the equilibrium adsorption of $\mathrm{Pb}^{2+}$ from aqueous solution (a) Langmuir (b) and Freundlich (c) isotherm models for $\mathrm{Pb}^{2+}$ removal by PAMAM-MNC
The pseudo-second-order kinetic model was developed based on the assumption that the rate-limiting steps are chemisorptions due to valence forces through electrons exchange or sharing between adsorbent and adsorbate (Heidari et al. 2009; Reddad et al. 2002). Following this model, it indicates that interaction between $\mathrm{Pb}^{2+}$ and PAMAM-MNC adsorbent is mainly chemical adsorption.

\section{Effect of adsorbent dosage on adsorption capacity of $\mathrm{Pb}^{2+}$}

Another important parameter is the effect of adsorbent dosage on the $\mathrm{Pb}^{2+}$ adsorption capacity value which was studied in 10-40 mg of PAMAM-MNC, under constant conditions. Results reported in Fig. 7 showed that the removal of lead ions from solution increased by increasing adsorbent dose. However, the adsorption capacity was slowly decreased as amount of adsorbent increased. This observation is attributed to the splitting effect of flux or concentration gradient between $\mathrm{Pb}^{2+}$ ions and adsorbent (Metin et al. 2013).

\section{Effect of initial $\mathrm{Pb}^{2+}$ concentration and adsorption isotherms}

The effect of the initial $\mathrm{Pb}^{2+}$ concentration (ranging from 300 to $1000 \mathrm{mg} / \mathrm{L}$ ) onto the adsorption capacity of PAMAM-MNC was studied under optimum $\mathrm{pH}$ as shown in Fig. 8. The adsorption capacity of $\mathrm{Pb}^{2+}$ increases with increasing initial $\mathrm{Pb}^{2+}$ concentration until $600 \mathrm{mg} / \mathrm{L}$, and then it remains constant.

In addition, to study the adsorption isotherm, two isotherm models introduced by Langmuir and Freundlich were applied (Foo and Hameed 2010). The Langmuir model is represented according to Eq. (6):

$\frac{C_{\mathrm{e}}}{Q_{\mathrm{e}}}=\frac{C_{\mathrm{e}}}{Q_{\mathrm{m}}}+\frac{1}{Q_{\mathrm{m}} k_{l}}$

while Freundlich isotherm equation can be represented as Eq. (7):

$\ln Q_{\mathrm{e}}=\ln k_{\mathrm{F}}+\frac{1}{n} \ln C_{\mathrm{e}}$

where $Q_{\mathrm{e}}$ and $Q_{\mathrm{m}}$ (mg/g) show the equilibrium and maximum adsorption capacity of $\mathrm{Pb}^{2+}, C_{\mathrm{e}}(\mathrm{mg} / \mathrm{L})$ is the equilibrium $\mathrm{Pb}^{2+}$ concentration and $k_{1}$ and $k_{\mathrm{F}}$ are the Langmuir and Freundlich adsorption constants, 
Table 4 Adsorption isotherm parameters of Langmuir and Freundlich models

\begin{tabular}{|c|c|c|c|c|c|c|c|}
\hline & \multicolumn{4}{|c|}{ Langmuir isotherm model } & \multicolumn{3}{|c|}{ Freundlich isotherm model } \\
\hline & $\overline{Q_{\max }(\mathrm{mg} / \mathrm{g})}$ & $k_{1}(\mathrm{~L} / \mathrm{mg})$ & $R^{2}$ & $R_{1}$ & $k_{\mathrm{F}}\left(\mathrm{mg}^{1-(1 / n)} \mathrm{L}^{1 / n} / \mathrm{g}\right)$ & $n$ & $R^{2}$ \\
\hline $\mathrm{Pb}^{2+}$ & 333 & 0.098 & 0.999 & $0.0101-0.0329$ & 288.4437 & 86.96 & 0.8617 \\
\hline
\end{tabular}
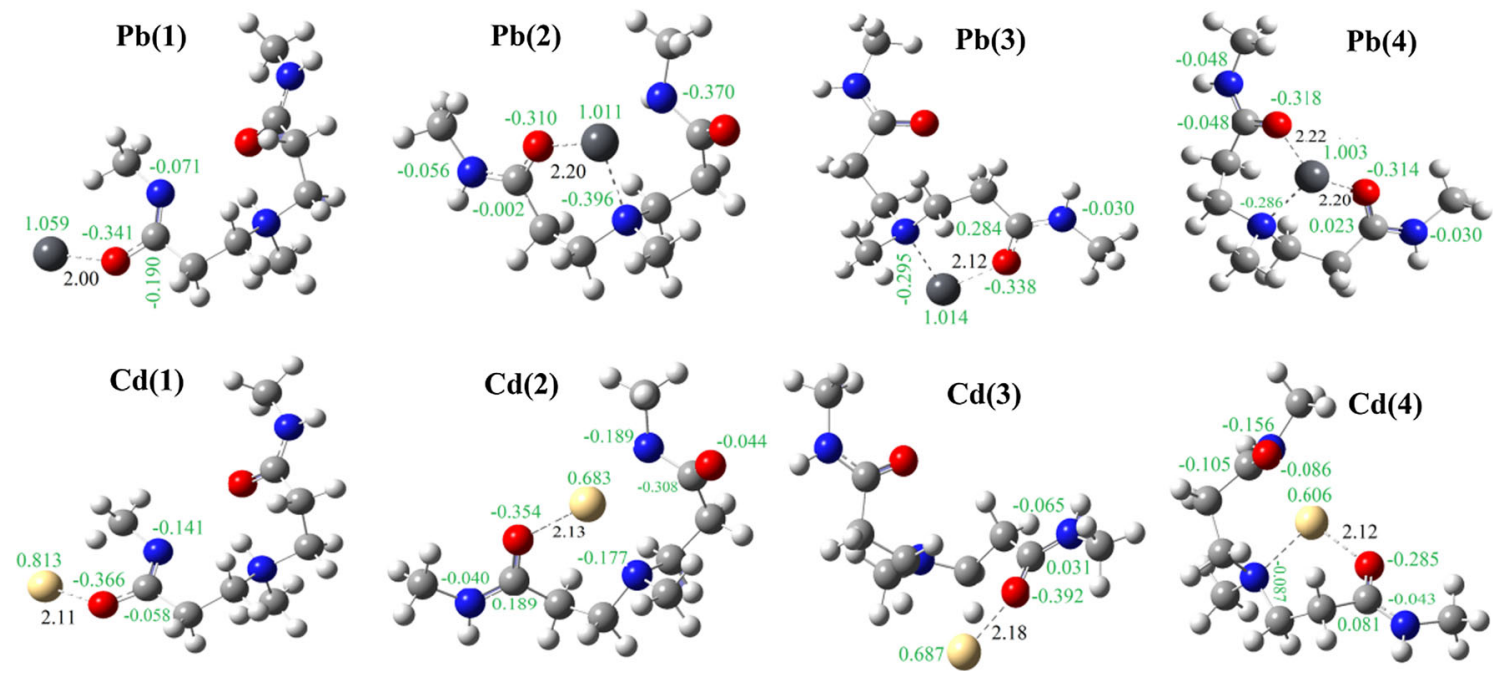

Fig. 9 Optimized models of $\mathrm{Pb}^{2+}$ and $\mathrm{Cd}^{2+}$ ions interaction with different sites of a segment of PAMAM dendrimer

Table 5 Adsorption free energies ( $\mathrm{kcal} / \mathrm{mol})$ between lead and cadmium ions with different sites of a segment of PAMAM dendrimer as calculated at the B3LYP method

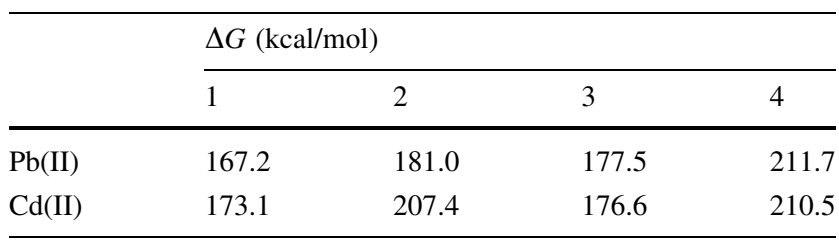

respectively. The plots of $C_{\mathrm{e}} / Q_{\mathrm{e}}$ versus $C_{\mathrm{e}}$ and $\ln \left(Q_{\mathrm{e}}\right)$ versus $\ln \left(C_{\mathrm{e}}\right)$ were obtained in a linear form according to Fig. 8b, c. Table 4 lists the calculated constants and correlation coefficients of Langmuir and Freundlich isotherms. Comparison of the correlation coefficients $\left(R^{2}\right)$ derived from both models indicated that Langmuir model provides a better fit of the experimental data and properly describes adsorption behavior of $\mathrm{Pb}^{2+}$ on the prepared adsorbent.

Moreover, Langmuir model can be applied to predict the type of adsorption process using dimensionless equilibrium factor $R_{1}$ (Zhang et al. 2013a):

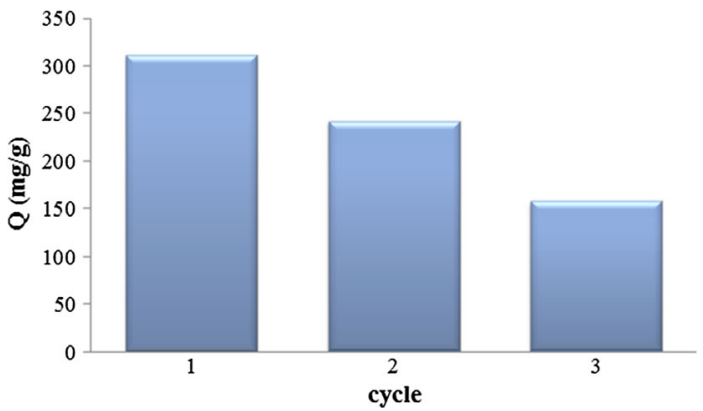

Fig. 10 Reusability of the adsorbents

$R_{1}=\frac{1}{1+k_{1} C_{0}}$

where $C_{0}(\mathrm{mg} / \mathrm{L})$ is the initial concentration of $\mathrm{Pb}^{2+} \cdot R_{1}$ value indicates the adsorption process could be favorable as $0<R_{1}<1$ or unfavorable as $R_{1}>1$. When $R_{1}$ is 0 or 1 , the type of adsorption process is irreversible or linear, respectively. Accordingly, in this study, the $R_{1}$ value given in Table 4 indicates favorable adsorption between lead ions and the prepared adsorbent. 


\section{Computational study}

Computational methods such as density functional theory (DFT) are valuable tools for understanding the chemical reactivity systems (Zhao et al. 2014). Therefore, in order to analyze metal adsorption onto the PAMAM-MNC and to further elucidate the adsorption mechanism, theoretical calculations were performed applying density functional theory (DFT) method (Saleh et al. 2013). The adsorption free energies of $\mathrm{Pb}$ (II) and $\mathrm{Cd}(\mathrm{II})$ toward various positions of a segment of PAMAM-MNC were calculated, as shown in Fig. 9, and the results are summarized in Table 5. The predicted adsorption free energies of $\mathrm{Pb}(\mathrm{II})$ and $\mathrm{Cd}(\mathrm{II})$ are in the range of $(167-212 \mathrm{kcal} / \mathrm{mol})$ and $(173-210 \mathrm{kcal} /$ mol), respectively. The adsorption free energies between both metal ions and all sites revealed strong interaction between metal ions and adsorbent. Nevertheless, the lead and cadmium ions interaction with adsorbent in $\mathrm{Pb} 4$ and Cd4 situations is stronger compared with the other studied situations (see Fig. 9). Moreover, the point charges and bond length $r(\mathrm{~Pb}-\mathrm{O}$ and $\mathrm{Cd}-\mathrm{O})$ were also calculated and results are indicated in Fig. 9; the less positive point charges in the $\mathrm{Pb}$ and $\mathrm{Cd}$ ions at $\mathrm{Pb} 4$ and $\mathrm{Cd} 4$ situations are in agreement with adsorption free energy results. These strong interactions between $\mathrm{Pb}(\mathrm{II})$ and PAMAM-MNC adsorbent resulted in high adsorption capacity of adsorbent, which is consistent with experimental observations.

\section{Recovery study}

For practical implementation, an efficient adsorbent should exhibit not only high adsorption capacity but also high reusability in order to reduce the overall cost of the adsorption process (Ge et al. 2012). The reusability for PAMAM-MNC adsorbent was then evaluated by comparing adsorption capacity of lead ions on regenerated and fresh adsorbent as shown in Fig. 10. It is found that although adsorption capacity of $\mathrm{Pb}^{2+}$ decreased after three cycles, the $Q$ value still reaches $155 \mathrm{mg} / \mathrm{L}$. Nevertheless, the value of $Q_{\mathrm{m}}$ is still larger than previously reported adsorbent. Therefore, our reusability studies suggest that PAMAM-MNC adsorbent can be repeatedly used as an efficient adsorbent for removal of $\mathrm{Pb}^{2+}$ ions from aqueous solution.

\section{Conclusion}

In conclusion, we have successfully designed and synthesized a new magnetic nanocomposite followed by modification of its surface with poly(amidoamine) dendrimer.
Then, we applied it to the uptake of $\mathrm{Pb}$ (II) ions from aqueous solution. IR, XRD, TGA, SEM, TEM and CHN analyses were used for characterization of the adsorbent. The effect of different experimental conditions such as solution $\mathrm{pH}$, contact time, adsorbent amount and initial concentration was thoroughly investigated and optimized for obtaining an improved adsorption process. The maximum adsorption capacity for lead ion was found $310 \mathrm{mg} / \mathrm{g}$ at $\mathrm{pH}=5-6$. Notably also, kinetic study clarified that experimental data fit well with the pseudo-second-order model as opposed to pseudo-first-order model. As well, the $\mathrm{Pb}^{2+}$ ions adsorption is well described by Langmuir isotherm model. Moreover, theoretical calculations (DFT) predicted the high adsorption free energies of $\mathrm{Pb}$ (II) and $\mathrm{Cd}(\mathrm{II})$ ions toward various adsorption sites. Taken the above observations into considerations, one can conclude that PAMAM-graft-poly(methyl acrylate) can be successfully applied for removal of heavy metal, especially lead from wastewater.

Acknowledgments We would like to thank Ms. Mehrnoosh Naderi for her help in the atomic absorption spectroscopy analysis.

\section{References}

Alsohaimi IH, Wabaidur SM, Kumar M, Khan MA, Alothman ZA, Abdalla MA (2015) Synthesis, characterization of PMDA/ TMSPEDA hybrid nano-composite and its applications as an adsorbent for the removal of bivalent heavy metals ions. Chem Eng J 270:9-21

Badruddozaa AZM, Shawon ZBZ, Danie TWJ, Hidajata K, Uddin MS (2013) $\mathrm{Fe}_{3} \mathrm{O}_{4} /$ cyclodextrin polymer nanocomposites for selective heavy metals removal from industrial wastewater. Carbohydr Polym 91:322-332

Belkacem M, Khodir M, Abdelkrim S (2008) Treatment characteristics of textile wastewater and removal of heavy metals using the electroflotation technique. Desalination 228:245-254

Bourque SC, Maltais F, Xiao WJ, Tardif O, Alper H, Arya P, Manzer LE (1999) Hydroformylation reactions with rhodium-complexed dendrimers on silica. J Am Chem Soc 121:3035-3038

Campbell BC, Elliott HL, Meredith PA (1981) Lead-exposure and renal-failure: does renal insufficiency influence lead kinetics. Toxicol Lett 9:121-124

Crini G (2005) Recent developments in polysaccharide-based materials used as adsorbents in wastewater treatment. Prog Polym Sci 30:38-70

Ezzeddine Z, Batonneau-Gener I, Pouilloux Y, Hamad H, Saad Z, Kazpard V (2015) Divalent heavy metals adsorption onto different types of EDTA-modified mesoporous materials: effectiveness and complexation rate. Microporous Mesoporous Mater 212:125-136

Foo KY, Hameed BH (2010) Insights into the modeling of adsorption isotherm systems. Chem Eng J 156:2-10

Ge F, Li MM, Ye H, Zhao BX (2012) Effective removal of heavy metal ions $\mathrm{Cd}^{2+}, \mathrm{Zn}^{2+}, \mathrm{Pb}^{2+}, \mathrm{Cu}^{2+}$ from aqueous solution by 
polymer-modified magnetic nanoparticles. J Hazard Mater 211-212:366-372

Ghaffari A, Husain SW, Tehrani MS, Anbia M, Azar PA (2015) Highly efficient adsorption of hexavalent chromium from the aqueous system using nanoporous carbon modified with tetraethylenepentamine. Int $\mathbf{J}$ Environ Sci Technol 12:1835-1844

Gurer-Orhan H, Sabir HU, Ozgunes H (2004) Correlation between clinical indicators of lead poisoning and oxidative stress parameters in controls and lead-exposed workers. Toxicology 195:147-154

Heidari A, Younesi H, Mehraban Z (2009) Removal of Ni(II), Cd(II), and $\mathrm{Pb}$ (II) from ternary aqueous solution by amino functionalized mesoporous and nanomesoporous silica. Chem Eng $\mathrm{J}$ 153:70-79

Ho YS, McKay G (1998) A comparison of chemisorption kinetic models applied to pollutant removal on various sorbents. Process Saf Environ Prot 4:332-340

Jiang R, Tian J, Zheng H, Qi J, Sun S, Li X (2015) A novel magnetic adsorbent based on waste litchi peels for removing $\mathrm{Pb}$ (II) from aqueous solution. J Environ Manag 155:24-30

Jin GP, Zhu XH, Li CY, Fu Y, Guan JX, Wu XP (2013) Tetraoxalyl ethylenediamine melamine resin functionalized coconut active charcoal for adsorptive removal of $\mathrm{Ni}(\mathrm{II}), \mathrm{Pb}$ (II) and $\mathrm{Cd}$ (II) from their aqueous solution. J Environ Chem Eng 1:736-745

Kosa SA, Al-Zhrani G, Abdel Salam M (2012) Removal of heavy metals from aqueous solutions by multi-walled carbon nanotubes modified with 8-hydroxyquinoline. Chem Eng J 181-182:159-168

Lagergren S (1898) About the theory of so-called adsorption of soluble substances. K Sven Vetenskapsakad Handl 24:1-39

Lee ME, Park JH, Chung JW, Lee CY, Kang S (2015a) Removal of $\mathrm{Pb}$ and $\mathrm{Cu}$ ions from aqueous solution by $\mathrm{Mn}_{3} \mathrm{O}_{4}$-coated activated carbon. J Ind Eng Chem 21:470-475

Lee JY, Chen CH, Cheng S, Li HY (2015b) Adsorption of Pb(II) and $\mathrm{Cu}$ (II) metal ions on functionalized large-pore mesoporous silica. Int J Environ Sci Technol. doi:10.1007/s13762-015-0841$\mathrm{y}$

Liu X, Hu Q, Fang Z, Zhang X, Zhang B (2009) Magnetic chitosan nanocomposites: a useful recyclable tool for heavy metal ion removal. Langmuir 25:3-8

Lu AH, Salabas EL, Angew FS (2007) Magnetic nanoparticles: synthesis, protection, functionalization, and application. Chem Int Ed 46:1222-1244

Mahmoud ME, Abdelwahab MS, Fathallah EM (2013) Design of novel nano-sorbents based on nano-magnetic iron oxide-boundnano-silicon oxide-immobilized-triethylenetetramine for implementation in water treatment of heavy metals. Chem Eng J 223:318-327

Metin A, Çiftçi H, Alver E (2013) Efficient removal of acidic dye using low-cost biocomposite beads. Ind Eng Chem Res 52:10569-10581

Minamisawa M, Minamisawa H, Yoshida S, Takai N (2004) Adsorption behavior of heavy metals on biomaterials. J Agric Food Chem 52:5606-5611

Naiya TK, Bhattacharya AK, Das SK (2009) Adsorption of Cd(II) and $\mathrm{Pb}(\mathrm{II})$ from aqueous solutions on activated alumina. J Colloid Interface Sci 333:14-26
Ozdes D, Duran C, Senturk HB (2011) Adsorptive removal of Cd(II) and $\mathrm{Pb}(\mathrm{II})$ ions from aqueous solutions by using Turkish illitic clay. J Environ Manag 92:3082-3090

Pang FM, Kumar P, Teng TT, Mohd Omar AK, Wasewar KL (2011) Removal of lead, zinc and iron by coagulation-flocculation. J Taiwan Inst Chem Eng 42:809-815

Pourjavadi A, Hosseini SH, Hosseini ST, Aghayeemeibody SA (2012) Magnetic nanoparticles coated by acidic functionalized poly(amidoamine) dendrimer: effective acidic organocatalyst. Catal Commun 28:86-89

Reddad Z, Gerente C, Andres Y, Cloirec PL (2002) Adsorption of several metal ions onto a low-cost biosorbent: kinetic and equilibrium studies. Environ Sci Technol 36:2067-2073

Repo E, Warchol JK, Bhatnagar A, Mudhoo A, Sillanpaa M (2013) Aminopolycarboxylic acid functionalized adsorbents for heavy metals removal from water. Water Res 47:4812-4832

Saleh TA, Gupta VK, Al-Saadi AA (2013) Adsorption of lead ions from aqueous solution using porous carbon derived from rubber tires: experimental and computational study. J Colloid Interface Sci 396:264-269

Shan C, Ma Z, Tong M, Ni J (2015) Removal of $\mathrm{Hg}$ (II) by poly(1vinylimidazole)-grafted $\mathrm{Fe}_{3} \mathrm{O}_{4} @ \mathrm{SiO}_{2}$ magnetic nanoparticles. Water Res 69:252-260

Shekinah P, Kadirvelu K, Kanmani P, Senthilkumar P, Subburam V (2002) Adsorption of lead (II) from aqueous solution by activated carbon prepared from Eichhornia. J Chem Technol Biotechnol 77:458-464

Song J, Oh H, Kong H, Jang J (2011) Polyrhodanine modified anodic aluminum oxide membrane for heavy metal ions removal. J Hazard Mater 187:311-317

Spartan '06V102', Wavefunction, Inc, Irvine

Tan Y, Chen M, Hao Y (2012) High efficient removal of Pb(II) by amino-functionalized $\mathrm{Fe}_{3} \mathrm{O}_{4}$ magnetic nano-particles. Chem Eng J 191:104-111

Tang SCN, Lo IMC (2013) Magnetic nanoparticles: essential factors for sustainable environmental applications. Water Res 47:2613-2632

Tang B, Yuan L, Shi T, Yu L, Zhu Y (2009) Preparation of nanosized magnetic particles from spent pickling liquors by ultrasonic-assisted chemical coprecipitation. J Hazard Mater 163:1173-1178

Wdjtowicz A, Stokmosa A (2002) Removal of heavy metal ions on smectite ion-exchange column. Pol J Environ Stud 11:97-101

Wu S, Li F, Xu R, Wei S, Li G (2010) Synthesis of thiolfunctionalized MCM-41 mesoporous silicas and its application in $\mathrm{Cu}(\mathrm{II}), \mathrm{Pb}(\mathrm{II}), \mathrm{Ag}(\mathrm{I})$, and $\mathrm{Cr}(\mathrm{III})$ removal. J Nanopart Res 12:2111-2124

Xin X, Wei Q, Yang J, Yan L, Feng R, Chen G, Du B, Li H (2012) Highly efficient removal of heavy metal ions by aminefunctionalized mesoporous $\mathrm{Fe}_{3} \mathrm{O}_{4}$ nanoparticles. Chem Eng $\mathrm{J}$ 184:132-140

Yamaura M, Camilo RL, Sampaio LC, Macedo MA, Nakamura M, Toma HE (2004) Preparation and characterization of (3-aminopropyl)triethoxysilane-coated magnetite nanoparticles. J Magn Magn Mater 279:210-217

Zhang J, Zhai S, Li S, Xiao Z, Song Y, An Q, Tian G (2013a) Pb(II) removal of $\mathrm{Fe}_{3} \mathrm{O}_{4} @ \mathrm{SiO}_{2}-\mathrm{NH}_{2}$ core-shell nanomaterials 
prepared via a controllable sol-gel process. Chem Eng J 215-216:461-471

Zhang YR, Wang SQ, Shen SL, Zhao BX (2013b) A novel water treatment magnetic nanomaterial for removal of anionic and cationic dyes under severe condition. Chem Eng J 213:258-264
Zhao F, Tang WZ, Zhao D, Meng Y, Yin D, Sillanpää M (2014) Adsorption kinetics, isotherms and mechanisms of $\mathrm{Cd}(\mathrm{II}), \mathrm{Pb}(\mathrm{II})$, $\mathrm{Co}$ (II) and $\mathrm{Ni}$ (II) by a modified magnetic polyacrylamide microcomposite adsorbent. J Water Process Eng 4:47-57 